\title{
EDUCAÇÃO AMBIENTAL E A ÉTICA DA RESPONSABILIDADE
}

Maria Keila Jeronimo ${ }^{1}$

Denis Barros de Carvalho ${ }^{2}$

Resumo: A natureza sofre transformações por meio da ação humana. Com o advento da tecnociência, a capacidade de intervenção modificou-se assustadoramente, degradando o ethos, e pondo em risco a vida de todos os seres vivos, imersos em uma crise ambiental. A Educação Ambiental é um importante meio de transformação das ações humanas. Nos valemos do Princípio Responsabilidade, proposto por Hans Jonas, como um novo agir para a civilização tecnológica. Analisamos sua possível contribuição no âmbito da ética ambiental para o desenvolvimento da Política Nacional de Educação Ambiental (LEI o 9.795/ 1.999), como política pública voltada para o agir coletivo, prezando pelas ações de co-participação para o bem socioambiental.

Palavras-chave: Educação Ambiental; Princípio Responsabilidade; Hans Jonas.

Abstract: Nature undergoes transformations by human action. With the rise of technoscience, the capacity for intervention has disturbingly shifted, degrading the ethos, and putting the lives of all living beings at risk, which are immersed in an environmental crisis. Thus, environmental education is an important tool for transforming human actions. We use the Principle of Responsibility, proposed by Hans Jonas, as a new way of behaving in a technological civilization. We analyzed his possible contributions in the scope of environmental ethics to the development of the National Policies for Environmental Education (Law No. 9.795/1.999), as a public policy aimed at collective action, valuing the measures of co-participation for socio-environmental benefit.

Keywords: Environmental Education; Principle of Responsibility; Hans Jonas.

${ }^{1}$ Professora do Instituto Federal de Educação, Ciência e Tecnologia do Piauí - IFPI.

E-mail: keilajeronimo@hotmail.com. Link para o Lattes: http://lattes.cnpq.br/6713518694881779

2Professor da Universidade Federal do Piauí - UFPI. E-mail: denispsi@hotmail.com.

Link para o Lattes: http://lattes.cnpq.br/6114958483289396

Revbea, São Paulo, V. 15, № 5: 424-439, 2020. 


\section{Introdução}

Ao longo da história da humanidade, a relação do ser humano com a natureza está marcada por fatores econômicos, políticos, sociais e religiosos, os quais estão ligados às ideias de mudança e de progresso ${ }^{3}$, seja de sobrevivência individual ou coletiva. Tanto um macro acontecimento, como as Grandes Navegações do século XV, quanto o desmatamento e a queima de alguns hectares, que o pequeno agricultor realiza para garantir a sua subsistência, têm ligação com um ou mais dos fatores citados.

Dessa forma, percebemos que o homem foi construindo uma cultura de poder e dominação, intermediada pela técnica, sobre a natureza e, com o seu aprimoramento, vem acentuando, cada vez mais, a capacidade de posse e destruição. O resultado disso são danos ambientais em todos os sentidos, muitos dos quais irreparáveis, com níveis alarmantes de degradação ambiental.

É nesse contexto de risco iminente de um colapso global que se deve pôr em dúvida e questão os padrões de vida atual, que alicerçados na técnica e no consumo crescente. $O$ homem deve, pois, refletir sobre o dano e a devastação provocados ao ethos 4 por meio de sua prática predatória, uma vez que a capacidade de suportar a habitação humana no futuro pode estar criticamente ameaçada (FOLTZ, 1995).

O homem é diretamente responsável pelas consequências de suas ações sobre a natureza, perspectiva que requer um modo de agir diferente do habitual. Por isso, o problema ambiental ganha, assim, uma dimensão ética.

O problema é, portanto, definido como envolvendo a profunda e anômala destruição pelos seres humanos de uma biosfera que consiste em "sistemas" sobrepostos ou auto-reguladores. Dado este ponto de vista, o problema de base é que pura e simplesmente nós não estamos a par do resto da natureza. Daqui segue a tarefa filosófica está em analisar e criticar os princípios da ação que levaram a esse desequilíbrio, isto é, em chegar a uma ética ambiental (FOLTZ, 1995, p. 22)

Pensar uma ética ambiental é (re)pensar sobre a relação homem/ natureza. Assim, refletir sobre a necessidade de mudança das nossas atitudes, vislumbrando um agir responsável perante toda a problemática ambiental; e,

\footnotetext{
3 Para Dupas (2007), o progresso, como hoje é caracterizado nos discursos hegemônicos de parte dominante das elites, não passa de um mito renovado por um aparato ideológico interessado em convencer que a história tem destino certo e glorioso. Neste sentido, para alguns, com altos riscos e custos de natureza social, ambiental e de sobrevivência da espécie, com possibilidade de provocar muitas catástrofes futuras.

${ }^{4}$ Cf. Vaz (1999), o qual afirma que a primeira acepção de ethos (com eta inicial) designa a morada do homem e do animal em geral.
} 
sobretudo, refletir sobre a Educação Ambiental como mudança efetiva, na concretude das ações humanas, na sociedade e na vivência cotidiana e coletiva, são atitudes imprescindíveis para se alcançar a estimada ética ambiental.

Por isso, a pergunta que fazemos é: qual o papel da Educação Ambiental, respaldada pela ética, como norteadora para mudança de ações que visam a responsabilidade, mediante o cenário de crise que acarreta muitas dúvidas, descrenças e incertezas, principalmente sobre como será nosso futuro na Terra?

Nesse sentido, o objetivo do presente artigo é refletir sobre os desafios da Educação Ambiental neste momento crítico, sobretudo de crise ambiental ${ }^{5}$. Assim, pensaremos em uma Educação Ambiental respaldada no Princípio Responsabilidade de Hans Jonas ${ }^{6}$, o qual poderá subsidiar a base unitária ética-Educação Ambiental.

A discussão aqui proposta, portanto, justifica-se pelo fato de tentar contribuir com esse tema frente a urgência dos problemas atuais, por isso, pensar sobre a Educação Ambiental é tão pertinente e importante. Esse debate é fruto de uma pesquisa de mestrado, a qual culminou nesta reflexão. Entendemos, no entanto, que está longe de se dirimir todas as dúvidas que envolvem tal problemática mas, certamente, elas só poderão ser sanadas sendo desde já debatidas.

Assim, no presente trabalho, analisamos a possível contribuição da teoria jonasiana no âmbito da ética ambiental para o desenvolvimento da Política Nacional de Educação Ambiental (LEI no 9.795/ 1.999), como possibilidade de política pública voltada para o agir coletivo, prezando as ações de co-participação para o bem socioambiental, assentada na base unitária, indissociável, da ética-Educação Ambiental.

\footnotetext{
5 Em uma perspectiva semântico-filosófica, o termo crise assume uma dimensão de incerteza, de indeterminação, de perda de sentido de segurança de sustentabilidade. Acentua um certo sentido de ambiguidade, de tensão, de desequilíbrio conjuntural, de declínio em estruturas sociais e espirituais tradicionais, de riscos inquietantes, mas esse termo representa, também, um momento de mudança súbita, de decisão, de inflexão. (GONÇALVES NETO; ARAÚJO NETO, 2006, p. 16).

6 Hans Jonas (1903-1993) nasceu na Alemanha, filho de imigrantes judeus, na juventude foi muito influenciado pela religião. Em 1921, conheceu Martin Heidegger, quem iria influenciar seu pensamento de forma marcante e contundente. Viveu uma experiência de soldado na $2^{2}$ Guerra Mundial, o que fez refletir sobre a preservação da vida, sobretudo a vida do futuro. Jonas publicou duas obras para descrever seu pensamento de como será a Responsabilidade, primeiro com a publicação do livro The fenomenon of life: Toward a Philosphical Biology, traduzido por Princípio Vida, no qual, estabelece os parâmetros de uma filosofia da biologia e abre um novo caminho de reflexão sobre a precariedade da vida, mostrando o grande alcance filosófico dos temas de interesse da biologia. Porém, a obra apresenta o equívoco de isolar o homem do resto da natureza, imaginando-o desvinculado das outras formas de vida. Sua obra principal foi Das Prinzip Verantwortunf: Versuch einer ethic für die tecnologische Zivilisation (O Princípio Responsabilidade: ensaio de uma ética para a civilização tecnológica), na qual propõe novos parâmetros éticos para a sociedade tecnológica do nosso tempo.
} 


\section{A teoria jonasiana e a responsabilidade com as grações futuras}

Hans Jonas vivenciou vários acontecimentos no percurso do século XX, como a Segunda Guerra Mundial, as bombas atômicas, o holocausto, e isso influenciou sua reflexão filosófica, provocando mudanças profundas na sua compreensão sobre a existência diante do progresso científico e tecnológico. Por isso, em sua obra principal Princípio responsabilidade: ensaio de uma ética para a civilização tecnológica, publicado em 1979, assinala que novos imperativos éticos devem ser postos para a humanidade.

Do empreendimento jonasiano, para formalizar uma ética para sociedade tecnológica, abordaremos três pontos, os quais são importantes para a fundamentação da Educação Ambiental que visa uma sociedade de consumo: a técnica moderna como fator modificante da ação humana, a heurística do temor e, por fim, a responsabilidade para com a gerações futuras.

Logo, no prefácio da sua obra, Jonas argumenta que hoje, com o avanço tecnológico, a figura que melhor representa o ser humano é a imagem de Prometeu desacorrentado. Prometeu está de volta,

[...] definitivamente desacorrentado, ao qual a ciência confere forças antes inimagináveis e a economia o impulso infatigável, clama por uma ética que, por meio de freios voluntários, impeça o poder dos homens de se transformar em uma desgraça para eles mesmos. A tese de partida deste livro é que a promessa da tecnologia moderna se converteu em ameaça, ou que esta se associou àquela de forma indissolúvel. (JONAS, 2006, p. 21).

Assim, Prometeu liberto do castigo eterno das correntes que o prendiam e da ave de rapina que vem lhe devorar o fígado, agora ele está entregue unicamente a si mesmo e com poderes sempre mais eficazes, traduzido por Jonas como o poder tecnológico associado à economia. Logo, é neste panorama que o autor afirma que o momento clama por uma nova ética.

O pensador alemão coloca como primeira questão o modo como a técnica moderna afeta o nosso agir, refletindo sobre até que ponto ela torna o agir sob seu domínio algo diferente do que existiu ao longo dos tempos. Ele afirma que devido a essas transformações em nossa capacidade de agir, "impõe-se uma modificação na ética" (JONAS, 2006, p. 29).

Se antes da Revolução Industrial, a técnica era um tributo prestado à necessidade, agora é a mais significativa tarefa humana. Assim, somos tentados a crer que a vocação dos homens se encontra no contínuo progresso desse empreendimento, superando-se sempre a si mesmo, rumo a feitos cada vez maiores. Para Jonas (2006), o progresso tecnológico foi de tal maneira que o homo faber adquiriu o primado sobre o homo sapiens. E nada é mais ameaçador do que tal sucesso da tecnologia, o homo faber triunfou tanto sobre seu objeto externo, como na constituição interna do homo sapiens, do qual em 
outros tempos costumava ser uma parte servil. Deste modo, a tecnologia assume um significado ético por causa do lugar central que ora ocupa, subjetivamente, nos fins da vida humana.

Se a esfera do produzir invadiu o espaço do agir essencial, então, a moralidade deve invadir a esfera do produzir, da qual ela se mantinha afastada anteriormente, e deve fazê-lo como política pública. Em outras palavras, se o predomínio da dimensão fabricante invadiu o domínio da moralidade, agora é preciso restabelecer o equilíbrio.

Esse mesmo raciocínio recai sobre o âmbito da ética, se antes ela só dizia respeito ao homem, certamente a natureza como uma responsabilidade humana é decerto um novum sobre o qual uma nova teoria ética deve ser pensada. Dessa forma, a limitação antropocêntrica de toda ética tradicional não seria mais válida, pois, agora, significa procurar não só o bem humano, mas também o bem das coisas extra-humanas, isto é, ampliar o reconhecimento de "fins em si" para além da esfera do humano. E o novo agir humano significa que deveríamos levar em consideração mais do que somente o interesse "do homem", visto que nossa obrigação se estende para mais além, para toda a biosfera.

Para sustentar sua teoria, o pensador realiza uma análise, pontuando desde a antiguidade até o nosso tempo da sociedade tecnológica, do poder de transformação do homem sobre a natureza. Em sua análise, ele afirma que, com a faculdade auto-adquirida do discurso, da reflexão e da sensibilidade social, o homem constrói uma casa para sua existência, ou seja, o artefato da cidade, asseverando que "a violação da natureza e a civilização do homem caminham de mãos dadas" (JONAS, 2006, p. 32). A cidade, neste sentido, seria a maior obra humana, formando o domínio completo e único da responsabilidade humana. Já a natureza não era objeto da responsabilidade humana - ela cuidava de si mesma (JONAS, 2006, p. 33). Assim, era nesse quadro intra-humano que habitava toda ética tradicional, adaptada às dimensões do agir humano condicionado.

Todavia, devido à técnica, a distância entre a "cidade" (pólis) e a "natureza", foi suprimida: a "cidade dos homens", outrora um enclave no mundo não-humano espalha-se sobre a totalidade da natureza terrestre e usurpou seu lugar. A diferença entre o artificial e o natural desapareceu, o natural foi tragado pela esfera do artificial; simultaneamente, o artefato total, as obras do homem que transformaram o mundo, agindo sobre ele e por meio dele, criaram um novo tipo de "natureza", isto é, uma necessidade dinâmica própria com a qual a liberdade humana defronta-se em um sentido inteiramente novo.

Hans Jonas chama atenção para a ética na relação do homem com a natureza, afirmando que a ética tradicional não dá conta do problema ambiental do nosso tempo. Nesse sentido, o autor propõe um novo imperativo, conduzindo o modo de agir fundado no "Princípio Responsabilidade", no qual é defendido que, para que a vida no Planeta esteja assegurada, faz-se preciso que o homem:

Revbea, São Paulo, V. 15, № 5: 424-439, 2020. 
Aja de modo a que os efeitos da tua ação sejam compatíveis com a permanência de uma autêntica vida humana sobre a Terra; [...] Aja de modo a que os efeitos da tua ação não sejam destrutivos para a possibilidade futura de uma tal vida. (JONAS, 2006, p. 47).

Ele aponta para os perigos que a humanidade corre se permanecer trilhando os mesmos caminhos percorridos até agora, por isso, aponta a "Responsabilidade" como saída válida para os problemas emergentes produzidos pela racionalidade tecnológica.

Sendo assim, chegamos ao segundo ponto importante, que é a heurística do temor, o que recai automaticamente no terceiro ponto, que diz respeito a nossa responsabilidade com o futuro. Precisamos de um conhecimento aproximado do futuro previsível imediato da humanidade, pois o valor de uma realidade só se afirma em oposição à sua perda, omissão ou destruição. Só entendemos a sacralidade da vida, porque existe o assassinato, ou da verdade porque existe a mentira.

Então, no primeiro momento, devemos temer o que pode acontecer a todos os seres vivos no futuro, pensando em como a vida no futuro está ameaçada pela prática predatória do homem. Dessa forma, a ética da responsabilidade precisa distorcer hipoteticamente a condição humana futura, para sabermos o que desejamos realmente preservar. Segundo Jonas (2006, p. 71), "o saber se origina daquilo contra o que devemos nos proteger", logo, é nisso que consiste a heurística do medo. Diante disso, cabe a nós refletirmos sobre as ameaças para nos assegurarmos das normas que vislubrem a preservação da vida.

A heurística do medo não é a última palavra na ética, mas constitui o primeiro passo indispensável dela. Jonas segue afirmando:

[...] o reconhecimento do malum é infinitamente mais fácil do que o do bonum; é mais imediato, mais urgente, bem menos exposto a diferenças de opinião; acima de tudo, ele não é procurado: o mal nos impõe a sua simples presença, enquanto o bem pode ficar discretamente ali e continuar desconhecido, destituído de reflexão [...] (JONAS, 2006, p. 71).

Nesse sentido, partindo da heurística do temor, o primeiro dever da ética do futuro seria visualizar as consequências da sociedade moderna industrial-tecnológica. Numa ética do futuro, temos de antecipar as condições desastrosas. Ele diz: 
Portanto, o malum imaginado deve aqui assumir o papel do malum experimentado. Como essa representação não acontece automaticamente, ela deve ser produzida intencionalmente: portanto, obter uma projeção desse futuro torna-se um primeiro dever, por assim dizer introdutório, daquela ética que buscamos. (JONAS, 2006, p. 72).

E, para se imaginar como nossa ação pode afetar a vida no futuro, o segundo dever seria mobilizar o sentimento adequado à representação, pois o mal distante imaginado não suscita o mesmo receio que o mal presente. Assim, precisamos nos sensibilizar para este tipo de reflexão e imaginação. Ou seja, pensarmos o porquê de o futuro humano não influenciar tanto a nossa sensibilidade. Entretanto, ele deveria influenciar, já que deveríamos sentir as consequências pelas gerações futuras. Ele afirma:

O destino imaginado dos homens futuros, para não falar daquele do planeta, que não afeta nem a mim nem a qualquer outro que ainda esteja ligado a mim pelos laços do amor ou do convívio direto, não exerce essa mesma influência sobre o nosso ânimo; no entanto, ele o "devia" fazer, isto é, nós devíamos conceder-Ihe essa influência. (JONAS, 2006, p. 72).

Dessa maneira, a adoção dessa atitude, dessa disposição de se deixar afetar pela salvação ou pela desgraça das gerações vindouras é o segundo dever "introdutório" da ética da responsabilidade. Portanto, o primeiro dever é produzir tal sentimento, e o segundo é, instruídos por tal sentimento, sermos instados a evocar o temor correspondente.

Entretanto, as projeções futuras são incertas, e necessariamente a ética proposta por Jonas requer prognósticos a longo prazo, o que é muito difícil, porque isso associa-se com fatores múltiplos, como a complexidade de efeitos naturais e sociais, a surpreendente capacidade e vulnerabilidade humanas, a impossibilidade de prever invenções futuras, logo, excede qualquer previsão completa. Com isso, na visão do autor, devemos dar maior atenção aos prognósticos de catástrofe que aos de salvação.

Dado este aspecto, uma ética da precaução e da prevenção tem que ponderar muito mais as ameaças do que as benesses alcançadas pela tecnologia. Nesse sentido, ele afirma:

O grande empreendimento da tecnologia moderna, que não é nem paciente nem lento, comprime - como um todo e em muitos de seus projetos singulares - os muitos passos minúsculos do desenvolvimento natural em poucos passos colossais, e com isso despreza a vantagem daquela marcha lenta da natureza, cujo tatear é uma segurança para a vida. (JONAS, 2006, p. 77). 
Sendo assim, o fato de tomarmos o desenvolvimento nas nossas próprias mãos, substituído o acaso cego, que opera lentamente, por um planejamento consciente e de rápida eficácia, fiando-se na razão, longe de oferecer ao homem uma perspectiva mais segura de uma evolução bemsucedida, produz uma incerteza e um perigo totalmente novos.

Nesse contexto, o desenvolvimento tecnológico tende a adquirir uma dinâmica própria irreversível, como também autopropulsionados, e que ultrapassa o planejamento dos agentes. Se somos livres para darmos o primeiro passo, passamos a ser escravos nos subsequentes. Acerca disso, Jonas (2006, p. 79) nos diz que: "essas circunstâncias reforçam a obrigação de vigiar os primeiros passos, concedendo primazia às possibilidades de desastre seriamente fundamentadas".

Não podemos apostar o que não temos. Mas, se as nossas ações afetam os outros, elas precisam ser pensadas com ética, logo, apostar numa ação envolve algo que Ihes pertence. A diferença moral é entre arriscar ou violar os interesses dos outros nos nossos projetos, o que depende da casuística da responsabilidade. Dessa forma, a responsabilidade para com as gerações nos diz que não temos o direito a escolher ou de arriscar a nãoexistência de gerações futuras, só por causa da nossa existência, pois temos o dever para com o que ainda não existe ou que pode vir a existir.

$\mathrm{Na}$ discussão que estabelece sobre como devemos cuidar da natureza, Jonas (2006, p. 352) é categórico quando afirma que:

A responsabilidade é o cuidado reconhecido como obrigação em relação a um outro ser, que se torna "preocupação" quando há uma ameaça à sua vulnerabilidade. Mas o medo está presente na questão original, com a qual podemos imaginar que se inicie qualquer responsabilidade ativa: o que pode acontecer a ele? Quanto mais obscura a resposta, maior se delineia a responsabilidade. Quanto mais no futuro longínquo situa-se aquilo que se teme, quanto mais distante do nosso bem-estar ou mal-estar, quanto menos familiar for o seu gênero, mais necessitam ser diligentemente mobilizadas a lucidez da imaginação e a sensibilidade dos sentidos.

De acordo com as palavras do autor, tudo aquilo que for oriundo da ação humana e que de alguma forma pode colocar em risco a vida, mesmo a mais longínqua, necessariamente se torna objeto da nossa responsabilidade. Nesse sentido, a nossa preocupação deve ser estendida a todos os seres vulneráveis que se encontram possivelmente em condição de serem afetados pela ação do homem, de tal forma que, assumindo esta responsabilidade, a humanidade venha a evitar a prática do mal, ou seja, que ela seja capaz de proteger ao invés de destruir. 


\section{A Política Nacional de Educação Ambiental e o Princípio da Responsabilidade}

Vislumbramos a Educação Ambiental como um importante elemento de debate dos problemas da sociedade atual, no sentido de produzir as sementes de renovação tanto no âmbito escolar como de toda a comunidade. É urgente pensar uma Educação Ambiental para a cidadania, que efetivamente cumpra seu papel de transformação social e provoque as mudanças necessárias que tanto a sociedade e a natureza precisam. Logo, essa área de ensino é um ato político baseado em valores para a transformação social.

A Educação Ambiental amparada pelo Princípio Responsabilidade tem muito a contribuir para a mudança que o mundo exige em tempos de crise ambiental, principalmente, no que concerne ao poderio tecnológico, racional e exagerado, maximizador da capacidade de destruição da ação humana. A partir desse princípio pode-se pensar uma sociedade ambientalmente responsável. Sob um fundamento ético, para o Princípio Responsabilidade, deve-se colocar em questão, inicialmente, o uso desenfreado da tecnologia e da ciência como caminho para perdurar o status quo imposto pela hegemonia econômica.

A ética da responsabilidade, a nosso ver, vai ao encontro da valorização e preservação da vida, do meio ambiente e de tudo que deve existir. Assim, as gerações presentes e as próximas estariam mais aptas para compreender e participar responsavelmente na sociedade global, questionando atitudes que pudessem pôr em risco a dignidade da vida em termos não só biológicos, mas sociológicos e culturais.

O sentido pedagógico da responsabilidade possui a tarefa de relembrar a moralidade, de relembrar que o futuro está implicado na esfera da decisão, do poder da liberdade. 0 aumento da massa crítica poderá despertar a consciência sobre os riscos de determinados empreendimentos tecnológicos. Por isso, a inovação do temor adquire um sentido de proteção e vigilância dos indefesos e frágeis (ZACANARO, 2011, p. 90).

Deste modo, podemos traduzir a proposta jonasiana como uma ação verdadeiramente pedagógica para o tempo que vivenciamos, pois aborda a necessidade de uma ética preocupada com aqueles que mais precisam de cuidado e proteção, os mais indefesos e frágeis. Segundo Jonas (2006), pensar sobre uma ética assentada no temor não diz respeito somente à prevenção contra os perigos, como forma de preservar a integridade física, mas também à própria essência do homem, na medida em que a transformação operada com a prática pedagógica transcende o caráter meramente instrumental. 
No âmbito da Educação Ambiental, a teoria da responsabilidade ajudará a levantar questões que poderão contribuir para a construção de uma sociedade ambientalmente responsável. Nesse contexto, referimo-nos à Educação Ambiental do ponto de vista tanto formal quanto informal, não colocando somente à escola como a única responsável pelo sucesso ou fracasso da vida em sociedade. A Educação Ambiental perfaz a totalidade das ações, desde aquelas veiculadas pelos meios de comunicação as ações públicas dos legisladores, do respeito intersubjetivo dentro do espaço público.

Nesse âmbito, enfatiza-se o importante papel da educação para o processo de conscientização acerca da realidade e, com isso, propor mudanças de atitudes que são necessárias e imprescindíveis para que a vida esteja assegurada na Terra. Posto que a tarefa da Educação Ambiental, no seu sentido amplo, é dar uma formação global de conhecimentos que auxiliam a gestão da vida no mundo, ela tem poder transformador.

A teoria jonasiana pautada na responsabilidade resgata o conceito de corresponsabilidade como meio para lidarmos com a realidade tecnológica a qual vivenciamos. Segundo esse filósofo, somos responsáveis pelas ações e consequências tanto do momento quanto do futuro, pois os viventes do presente bem como do futuro têm direito à vida. Dessa maneira, a coletividade deve preocupar-se com as decisões a serem tomadas, com vistas a levar em conta a limitação de ações destrutivas, e que ponham em risco a vida e os meios de permanência da vida.

Nessa perspectiva, trazer discussões sobre ética e Educação Ambiental faz-se necessário porque é preciso repensar os problemas advindos do avanço tecnológico, convocando a responsabilidade que devemos assumir perante todo o planeta e com as gerações futuras.

Por isso, vislumbra-se a ética da responsabilidade como possibilidade de fundamentação para Educação Ambiental. A esse respeito, Barreto; Garção (2010, p. 105) afirma que: "sua pesquisa em torno da crise e da atuação ética de forma ampliada aponta condições favoráveis para a instauração de uma Ética Ambiental ou Ética da Responsabilidade como paradigma fundativo para a Educação Ambiental".

Nesse sentido, se mostra a importância da ética da responsabilidade, a qual está voltada para o agir da coletividade, por isso, existem subsídios suficientes para pensar a ética da responsabilidade como fundamento para Educação Ambiental. Tal afirmação encontra-se no fato de que a educação, como política pública, deverá atender às necessidades urgentes que se encontram na sociedade tecnológica contemporânea. De acordo com Barreto; Garção (2010),

[...] a crise ambiental nos impele para um amplo debate éticoeducacional que reflita a exclusão de fronteiras disciplinares e se ancore nos princípios fundantes da ética da responsabilidade, enquanto proposta pedagógica que forneça novos elementos compatíveis com as ações e desenvolvimento 
de programas no âmbito das políticas públicas. Dessa forma, a ética da responsabilidade pode ser vista como subsídio teórico para uma fundamentação filosófica da Política Nacional de Educação Ambiental (BARRETO; GARÇÃO, 2010, p. 107).

Diante do exposto, a Política Nacional de Educação Ambiental - PNEA, instituída pela Lei n. 9.795/ 1999, trata de modo específico a questão da Educação Ambiental brasileira e declara no seu artigo 1ำ que: "a Educação Ambiental é um componente essencial e permanente da educação nacional, devendo estar presente, de forma articulada, em todos os níveis e modalidades do processo educativo, em caráter formal e não formal". Desse modo, percebemos que o poder público compreende a importância da Educação Ambiental em todos os níveis do processo educativo, tanto nas escolas quanto na comunidade em geral, ou seja, não formal. todos:

Segundo o artigo 1ำ da PNEA, compreende-se por Educação Ambiental

[...] os processos por meio dos quais o indivíduo e a coletividade constroem valores sociais, conhecimentos, habilidades, atitudes e competências voltadas para a conservação do meio ambiente, bem de uso comum do povo, essencial à sadia qualidade de vida e sua sustentabilidade.

Assim, vemos claramente que existe a necessidade de constituirmos uma nova relação do homem com a natureza, visando à mudança de valores e atitudes por meio de uma Educação Ambiental efetiva, a qual norteará a construção de uma realidade pautada na responsabilidade, com vista à sustentabilidade da vida e do planeta. Para alcançarmos tal objetivo, a sustentabilidade, devemos melhorar o processo educativo, fundamentando-o em princípios éticos que possam nortear uma nova proposta pedagógica direcionada à Educação Ambiental efetiva.

Desta maneira, vislumbra-se a ética fundamentada no princípio responsabilidade como subsídio para a formação da cidadania preocupada e responsável com o meio ambiente no qual vivemos. Podemos citar, ainda, no seu artigo 4ํㅜ o qual dispõe sobre os princípios básicos da Educação Ambiental:

I - o enfoque humanista, holístico, democrático e participativo; II - a concepção do meio ambiente em sua totalidade, considerando a interdependência entre o meio natural, o sócioeconômico e o cultural, sob o enfoque da sustentabilidade; III - pluralismo de ideias e concepções pedagógicas, na perspectiva da inter, multi e transdisciplinaridade; IV - a vinculação entre a ética, a educação, o trabalho e as práticas sociais; V - a garantia de continuidade e permanência do processo educativo; VI - a permanente avaliação crítica do processo educativo; VII - a abordagem articulada das questões 
ambientais locais, regionais, nacionais e globais; VIII - o reconhecimento e o respeito à pluralidade e à diversidade individual e cultural.

Tais princípios básicos descritos vão de encontro ao que temos visto da relação do homem com a natureza, das transformações sofridas por esta através da ação humana. Já faz um tempo que é muito comum se deparar com inúmeras formas de agressão ao meio ambiente como, por exemplo, a contaminação dos cursos de água, a poluição atmosférica, a devastação de florestas, a caça indiscriminada, a destruição do habitat da fauna. Todas essas formas de destruição são decorrentes do relacionamento da humanidade com a natureza, que teve início com um mínimo de interferência nos ecossistemas, culminando numa pressão exercida sobre os recursos naturais. Assim, justificase uma discussão interdisciplinar inadiável que possibilitará uma formação ética direcionada à Educação Ambiental.

Por isso, partindo da ética proposta por Hans Jonas, o princípio responsabilidade, o qual vislumbra que uma nova relação pode ser efetivada entre homem e natureza, não considerando o passado que é inalterado e sim o hoje, a ética da responsabilidade, a nosso ver, concerne na alternativa mais viável para estabelecer essa nova relação ao partir da responsabilidade, do cuidado e respeito por todas as formas de vida. Sendo assim, enseja o respeito com a biodiversidade, com vistas à sustentabilidade da nossa moradia.

Esse cenário deverá despertar a preocupação do poder público e de todo o mundo, exigindo posicionamentos necessários para modificar o comportamento do homem em relação à natureza. Essa é uma possibilidade de desenvolver um processo que assegure uma gestão responsável dos recursos do planeta de forma a preservar os interesses das gerações futuras e, ao mesmo tempo, atender as necessidades das gerações atuais. Com tais atitudes, e por meio da educação, sob um modelo que vislumbre a sustentabilidade, podemos indicar parâmetros da responsabilidade como um aporte ético para mudança pedagógica necessária e com reflexos positivos evidentes da qualidade de vida de todos.

De acordo com as Diretrizes Curriculares Nacionais para a Educação Ambiental-DCNEA ${ }^{7}$, no seu artigo $2^{\circ}$ :

A Educação Ambiental é uma dimensão da educação, é atividade intencional da prática social, que deve imprimir ao desenvolvimento individual um caráter social em sua relação com a natureza e com os outros seres humanos, visando potencializar essa atividade humana com finalidade de torná-la plena de prática social e de ética ambiental.

${ }^{7}$ Conselho Nacional de Educação, resolução n. 2, de 15 de junho de 2012. 
Nessa perspectiva, observamos que a Educação Ambiental é um processo mais específico de educação, que se propõe a despertar e a formar a preocupação individual e coletiva para as questões ambientais, orientada para desenvolver a consciência e participação do homem como cidadão planetário. Ou seja, os sujeitos precisam assumir os problemas ambientais como uma questão ética, social, econômica e política, cabendo a escola desenvolver essa consciência através de uma Educação Ambiental.

No artigo $5^{\circ}$ da PNEA, o qual dispõe sobre os objetivos fundamentais da Educação Ambiental, destacamos os seguintes:

I - o desenvolvimento de uma compreensão integrada do meio ambiente em suas múltiplas e complexas relações, envolvendo aspectos ecológicos, psicológicos, legais, políticos, sociais, econômicos, científicos, culturais e éticos; II - o estímulo e o fortalecimento de uma consciência crítica sobre a problemática ambiental e social; III - o incentivo à participação individual e coletiva, permanente e responsável, na preservação do equilíbrio do meio ambiente, entendendo-se a defesa da qualidade ambiental como um valor inseparável do exercício da cidadania; IV - o estímulo à cooperação entre as diversas regiões do País, em níveis micro e macrorregionais, com vistas à construção de uma sociedade ambientalmente equilibrada, fundada nos princípios da liberdade, igualdade, solidariedade, democracia, justiça social, responsabilidade e sustentabilidade; VI - o fortalecimento da cidadania, autodeterminação dos povos e solidariedade como fundamento para o futuro da humanidade.

Entre os objetivos fundamentais da Educação Ambiental, é possível destacar a importância do ser humano perceber-se como parte do meio ambiente e não como o todo. Com a Educação Ambiental, superamos a visão antropocêntrica e indicamos rotas para um biocentrismo responsável pelo resgate da dimensão ética da Educação Ambiental.

Contudo a Educação Ambiental por si só não resolverá os problemas ambientais planetários tão complexos, mas pode ser instrumento decisivo para isso, quando, por meio de seus princípios e objetivos, impulsiona ações cidadãs sobre direitos e obrigações com o meio ambiente. Em outras palavras, o homem ao conhecer a crise global e atuar na sua comunidade - e isso se consegue com a Educação Ambiental - garantiria uma mudança concreta no sistema. Enfim, os problemas do meio ambiente foram criados pelos homens e deles terão de vir soluções.

Deste modo, a conexão indissociável entre ética e Educação Ambiental (GRÜN, 2011) se faz necessária, principalmente, quanto à conduta humana em relação ao meio ambiente. Se o homem pautar suas ações em posturas éticas mínimas, respeitando a natureza, utilizando racionalmente os recursos por ela 
disponibilizados, e gerando tecnologias alternativas e menos agressivas, possivelmente não ocorrerão tantos crimes e acidentes ambientais. Como afirma Leff (2001, p. 256),

A Educação Ambiental fomenta novas atitudes nos sujeitos sociais e novos critérios de tomada de decisões dos governos, guiados pelos princípios de sustentabilidade ecológica e diversidade cultural, internalizando-os na racionalidade econômica e no planejamento do desenvolvimento. Isso implica educar para formar um pensamento crítico e prospectivo, capaz de analisar as complexas relações entre processos naturais e sociais, para atuar no ambiente com uma perspectiva global, mas diferenciada pelas diversas condições naturais e culturais que o definem.

Diante do exposto, fica evidente que precisamos de uma educação que cultive os valores da cidadania, a responsabilidade, a criticidade, a participação e a emancipação dos sujeitos; um ensino em que cada cidadão, por meio da interdisciplinaridade, aprenda o reconhecimento e o diálogo entre os vários saberes que compõe o âmbito do conhecimento, abrindo o leque de possibilidades para a tomada de decisões transformadoras a partir do meio ambiente natural ou construído no qual as pessoas se inserem e fazem parte como atores sociais. Essa visão do ponto de vista educacional, para nós, supera a dissociação entre o homem e natureza, mantendo uma relação responsável, dialógica e transformadora do mundo.

Para resolver nossos problemas devemos aprender a pensar para atuar conforme novas pautas, com maior consciência e compreensão das implicações ambientais de nossos atos. Nesse sentido, é o Princípio Responsabilidade o fundamento para uma Educação Ambiental, pois entendemos ser esta 0 instrumento de intervenção que dispomos para resultados de médio e longo prazo, numa sociedade imediatista e utilitarista, onde a qualidade de vida está intimamente relacionada com satisfação dos desejos, sem ponderar os custo e riscos que a vida, seja da humanidade como de todos os seres vivos, corre se continuarmos trilhando os mesmos caminhos.

Assim, a Educação Ambiental tendo como fundamentação a responsabilidade tem como desafio a ser percorrido entre outros ultrapassar a racionalidade utilitarista, podendo construir a possibilidade da ação política, no sentido de contribuir para formar uma coletividade que é responsável pelo mundo que habita. Somos obrigados a pensar uma Educação Ambiental como uma educação cidadã, mais que isso, uma educação planetária.

Nesse âmbito, podemos considerar que a Educação Ambiental nos abre a possibilidade de superarmos a condição de objetos de responsabilidade para sujeitos dela. Por isso, a ética de responsabilidade tem uma dimensão pedagógica que se desloca em todas as direções do nosso agir. Assim, como a tarefa da Educação Ambiental no seu sentido amplo é dar uma formação e 
visão global de conhecimentos interdisciplinar, os quais auxiliam a gestão da vida no mundo, a ética da responsabilidade poderá ser um bom instrumento na valorização da vida, do meio ambiente e de tudo que deve existir.

Toda educação é uma ação de diálogo entre seres humanos, logo, uma educação pode ser eficiente enquanto processo formativo. Na perspectiva de a ética ambiental para a vida, é exigido dos profissionais da educação uma postura de ação com responsabilidade, ou seja, habilidades de oferecer respostas mais adequadas às demandas, à medida que essas se apresentam. O conhecimento atual aponta para atitudes criativas, para a busca de soluções inéditas, para a liderança ética e para o resgate dos valores.

Nesse contexto, Hans Jonas propõe, para esse tipo de ação, o conceito de corresponsabilidade como mais apropriado para lidar com nossa realidade. Para o autor, somos responsáveis diretos não só pela situação presente, mas também pelas gerações futuras, pois elas têm igual direito à vida. Isso implica que tomemos decisões coletivas que imponham limites à sociedade tecnológica que nós mesmos criamos. No âmbito social, o homem não tem mais o controle sobre os efeitos intencionais e colaterais de sua ação e isso é tão mais verdadeiro quanto mais complexa é a sociedade.

\section{Conclusões}

O Princípio Responsabilidade proposto por Hans Jonas, tendo a responsabilidade como cerne de sua proposta ética, a nosso ver, se apresenta como uma saída válida para atual crise de valores, como também para a crise ambiental. Nesse sentido, a responsabilidade tem como objetivo a conscientização do homem em relação a sua obrigação frente ao ser, impondo o limite a sua liberdade de ação e ultrapassando a razão utilitarista e hedonista que despojou a natureza de valor e que a encara como objeto que pode ser manipulado e submetido aos seus interesses imediatos.

Por isso, Jonas (2006) assume-se como propositor de uma nova ordem ética em ruptura com a ética tradicional, antropocêntrica, do aqui e do agora, em favor de uma ética que inclua o futuro e a vulnerabilidade no seu horizonte com vista à preservação da vida. Diante disso, seu empreendimento tem por base o comprometimento com o que pode acontecer, com isso, coloca a heurística do temor, pois o que nos deve conduzir não seria a felicidade alcançada, mas, sim, o pior prognóstico de desastre, visto que só ele poderá frear os impulsos da ação humana.

Nesse contexto, o Princípio Responsabilidade se mostra como possibilidade de fundamentação para a Educação Ambiental, ou seja, uma educação-ética ambiental, que estabeleça novos elos do homem com a natureza e que vise o bem-estar de todos os seres vivos. Assim sendo, tal ensino visa a assegurar toda e qualquer possibilidade de vida sobre a Terra, como também assegurar a valorização da vida e a existência das gerações futuras. 
Portanto, apresentamos a teoria jonasiana e sua contribuição no âmbito da ética ambiental, para o desenvolvimento da Política Nacional de Educação Ambiental (PNEA, LEI no 9.795, de 27 de abril de 1999), como possibilidade de política pública voltada para o agir coletivo, prezando as ações de co-participação para o bem da sociedade, não pensando somente no presente, mas também preocupados com a vida do futuro.

\section{Agradecimentos}

À Secretaria Estadual de Educação do Estado do Maranhão - SEDUC/ MA, pelo apoio para capacitação, e à Universidade Federal do Piauí - UFPI, por tornar possível o mestrado da autora.

\section{Referências}

BARRETO, S.; GARÇÃO, E.S. Homem e natureza: o lugar paradigmático do princípio ético de Hans Jonas na Educação Ambiental. Pesquisa em Educação Ambiental. Sergipe, v.5, n. 1, 2010.

BRASIL. Lei no 9.795, de 27.4.1999. Dispõe sobre Educação Ambiental e institui a Política Nacional de Educação Ambiental, e dá outras providências. DOU 28.4.1999.

BRASIL. Ministério da Educação. Conselho Nacional de Educação/Câmara de Educação Ambiental. Parecer CNE/CP $\mathrm{n}^{0} 14 /$ 2012. Estabelece as Diretrizes Curriculares Nacionais para a Educação Ambiental. Diário Oficial da União, Brasília, DF, 18 jun. 2012. Seção 1, p. 70. Disponível em URL: $<$ http://portal.mec.gov.br/index.php?option=com content\&view=article\&id=17810\&ltemi $\mathrm{d}=866>$ Acessado em 12 de setembro de 2012.

FOLTZ, B.V. Habitar a Terra: Heidegger, ética ambiental e a metafísica da natureza. Trad. Jorge Seixas de Sousa. Lisboa: Instituto Piaget,1995.

DUPAS, G. Mito do progresso. Novos Estud. - CEBRAP [online] . 2007, n. 77, pp. 73-89. ISSN 1980-5403.

GONÇALVES NETO, J; ARAÚJO NETO, G. A. Modernidade e crise ambiental. In: MONTEIRO, M.S.L. (Org.). Teresina: Uma visão ambiental. Teresina: Editora Gráfica da UFPI, 2006, Vol. 1, p. 15-46.

GRÜN, M. Ética e Educação Ambiental: a conexão necessária. Campinas, SP: editora, 2011.

JONAS, H. O princípio responsabilidade: ensaio de uma ética para a civilização tecnológica. Trad. Marijane Lisboa e Luiz Barros Montez. Rio de janeiro: Contraponto/Editora da PUC-RIO, 2006.

JONAS, H. Ética, medicina e técnica. Lisboa: Vega, 1994.

LEFF, E. Saber ambiental: sustentabilidade, racionalidade, complexidade, poder. Trad. de Lúcia Mathilde Endlich Orth. Petrópolis, RJ: Vozes, 2001.

VAZ, H.C.L. Escritos de Filosofia II: Ética e cultura. São Paulo: Ed. Loyola, 1999.

ZACANARO, L. Ética para a civilização tecnológica: em diálogo com Hans Jonas. São Paulo: Centro Universitário São Camilo, 2011. 